\title{
Primary peristalsis is the major acid clearance mechanism in reflux patients
}

\author{
A Anggiansah, G Taylor, N Bright, J Wang, W A Owen, T Rokkas, A R Jones, W J Owen
}

\begin{abstract}
This study examined the clearance of gastric acid from the oesophagus in ambulant patients with gastrooesophageal reflux. Eighteen patients with proved reflux disease were studied, nine with (group 1) and nine without (group 2) endoscopic oesophagitis. Oesophageal pressure and pH were recorded over 24 hours. Pressures were measured by a probe with five sensors: a $5 \mathrm{~cm}$ long sensor in the lower oesophageal sphincter, three sensors in the body of the oesophagus, and one at the pharynx to detect swallowing. Oesophageal pH was monitored $5 \mathrm{~cm}$ above the lower oesophageal sphincter. Manometric activities were classified as either peristaltic or ineffective. The latter included simultaneous, non-transmitted, and low amplitude peristaltic contractions. A reflux episode was defined as starting when $\mathrm{pH}$ fell to less than 4 and ending when the pH rose to 5 . When the rise to pH 5 took place in three or more discrete steps after motor responses to gastrooesophageal reflux, the pH steps were labelled as initial change (I), middle changes (M), and last change (L). A total of 595 episodes of gastro-oesophageal reflux and 1626 associated motor events were analysed. Of these, $1331(81.9 \%)$ were classed as primary peristaltic activity, $174(10.7 \%)$ as primary ineffective activity, $46(2 \cdot 8 \%)$ as secondary peristaltic activity, and $75(4 \cdot 6 \%)$ as secondary ineffective activity. There were no significant differences in initial change (p>0.05), middle changes $(p>0.05)$, and last change ( $p>0.05)$ between group 1 and group 2. In all patients, the successive changes of $\mathrm{pH}$ in response to motor activity were significantly different $(\mathbf{p}=0.0001)$ between initial, middle, and last changes. Last change was significantly higher when compared with initial $(p=0.001)$ and middle changes $(p<0 \cdot 001)$. Primary oesophageal peristalsis was the most frequent motor response to gastrooesophageal reflux. The last motor activity during reflux showed the greatest change in $\mathbf{p H}$.

(Gut 1994; 35: 1536-1542)
\end{abstract}

Acid clearance from the oesophagus after gastro-oesophageal reflux depends on two important mechanisms; oesophageal peristalsis to return the displaced gastric content to the stomach and swallowing saliva to neutralise the residual acid that coats the oesophageal mucosa. ${ }^{1}$ It has been shown by simultaneous manometric and video-fluoroscopic recording of barium swallows that a minimal peristaltic amplitude of $30 \mathrm{~mm} \mathrm{Hg}$ is required to prevent retrograde movement of barium in the distal oesophagus. $^{2} 3$ Inadequate peristaltic amplitude, simultaneous contractions, or failed peristalsis result in little or no clearance of gastric content from the affected segment of the oesophagus.

Earlier studies using static manometry showed that peristaltic dysfunction, ineffective peristalsis, or a hypotensive lower oesophageal sphincter occurred in a significant number of patients with peptic oesophagitis. ${ }^{4}$ Previous studies used a non-physiological method of evaluating acid clearance, after a bolus of $0 \cdot 1 \mathrm{~N} \mathrm{HCL}$ acid had been infused into the oesophagus to simulate gastro-oesophageal reflux. The $\mathrm{pH}$ increments in response to swallows, taken on command at a fixed time interval were monitored. ${ }^{67}$ The oesophageal motor activity during acid reflux and the oesophageal acid clearance mechanisms in the ambulant non-hospitalised patients with gastro-oesophageal reflux, however, has not been fully studied.

This study aimed to investigate and compare the reflux induced oesophageal motor pattern between two groups of patients with objectively proved gastro-oesophageal reflux, those with (group 1) and those without (group 2) oesophagitis as demonstrated by endoscopy. Measurements were made with a recently developed 24 hour ambulatory pressure and $\mathrm{pH}$ monitoring system.

\section{Methods}

PATIENTS

Eighteen consecutive patients (16 men and two women), with a mean (SD) age of $47.6(9 \cdot 04)$ years (range 37-70), complaining of heartburn, regurgitation, dysphagia, or chest pain were studied. Patients were asked not to take an $\mathrm{H}_{2}$ antagonist for 48 hours, omeprazole for seven days, and (provided the prescriber agreed) motility altering drugs for $\mathbf{4 8}$ hours before the study. All patients underwent standard oesophageal manometry to exclude primary or secondary oesophageal motor disorders such as achalasia or scleroderma, followed by an ambulatory 24 hour oesophageal $\mathrm{pH}$ study to confirm the presence of abnormal gastro-oesophageal reflux. Of the 18 patients selected, nine had endoscopic oesophagitis (grade 1 and 2) (group 1) and nine had no evidence of macroscopic mucosal injury (group 2). 


\section{STANDARD MANOMETRY}

Oesophageal manometry was performed using a catheter with six, surface mounted miniature pressure transducers (Gaeltec, Isle of Skye, $\mathrm{UK}$ ) arranged at $5 \mathrm{~cm}$ intervals with the distal four sensors orientated at $90^{\circ}$ radially to each other. The catheter was passed transnasally into the stomach, and the study was performed with the patient in the sitting position. The mean lower oesophageal sphincter tonic pressure above intragastric pressure was recorded in $\mathrm{mm} \mathrm{Hg}$ and the upper margin of the lower oesophageal sphincter was located using the station pull-through technique. Oesophageal contractions in response to 10 wet swallows ( $5 \mathrm{ml}$ boluses of water given via a syringe) were recorded.

\section{AMBULATORY 24 HOUR OESOPHAGEAL PH MONITORING}

Ambulatory oesophageal $\mathrm{pH}$ monitoring (Synectics Medical, Sweden) was performed using an antimony $\mathrm{pH}$ sensor. The sensor was calibrated in $\mathrm{pH} 7$ and $\mathrm{pH} 1$ buffer solutions before each test and was rechecked afterwards. In all cases, the electrode drift was within $0.5 \mathrm{pH}$ units. ${ }^{8}$ The $\mathrm{pH}$ catheter was inserted transnasally until the sensor registered a low $\mathrm{pH}$, to ensure that the probe had reached the gastric region and was not curling inside the oesophagus, then it was slowly withdrawn. The $\mathrm{pH}$ sensor was positioned $5 \mathrm{~cm}$ above the manometrically defined upper margin of the lower oesophageal sphincter. Both the $\mathrm{pH}$ and reference catheters were secured to the patient with micropore tape (3M, St Paul, USA) and connected to a digitrapper. Each patient was provided with a form and used it to keep a record of their activity. Patients were also provided with a table of $\mathrm{pH}$ values associated with food and drink and instructed to avoid taking food and drink with a $\mathrm{pH}<4$. Patients were asked to press the event marker on the digitrapper when symptoms or other events occurred and were encouraged to pursue normal activities for the duration of the study.

A fall in the oesophageal $\mathrm{pH}$ to less than pH 4 was defined as the start of a reflux episode which ended when $\mathrm{pH}$ rose to 5 . Upright time was defined as a standing or sitting position including meal times. The time when the patient was supine was defined as when the patient was lying down. The total time was the 24 hour recording period. The computer and software package (Oesophagraph, Synectics Medical, Sweden) was used to calculate the percentage of total reflux time, the percentage of upright and supine reflux, the total number of reflux episodes, total number of reflux episodes longer than five minutes, and the longest reflux episode. These reflux parameters were used to evaluate the Johnson and DeMeester score. ${ }^{9} \mathrm{~A}$ score of greater than 14.7 based on our estimate of the 95th centile of normal volunteers, was used to indicate abnormal acid exposure and to differentiate pathological reflux from physiological reflux.
AMBULATORY PRESSURE AND PH MONITORING

\section{Design of pressure and $\mathrm{pH}$ measuring assembly \\ Pressure measuring assembly}

The five pressure sensor catheter (Gaeltec, Isle of Skye, UK) consisted of a $5 \mathrm{~cm}$ long sensor to monitor lower oesophageal sphincter pressure, the sphinctometer, ${ }^{10}$ three surface mounted miniature strain-gauge pressure sensors placed at $2.5 \mathrm{~cm}, 7.5 \mathrm{~cm}$, and $12.5 \mathrm{~cm}$ above the sphinctometer to measure oesophageal body pressures, and a fifth pressure sensor similar to the others, $24.5 \mathrm{~cm}$ above to the sphinctometer to detect pharyngeal pressure rise or cricopharyngeal activity associated with voluntary swallows. The proximal four sensors were orientated at $90^{\circ}$ radially to each other. The sphinctometer has been developed specifically for ambulatory measurements of lower oesophageal sphincter behaviour. It consisted of a $5 \mathrm{~cm}$ long, oil filled silastic chamber connected to a standard Gaeltec strain-gauge pressure sensor. It was positioned in a similar manner to the Dent sleeve ${ }^{11}$ and recorded the integrated output of the pressure and length components of the lower oesophageal sphincter, thereby reducing the errors associated with point pressures and non-radially symmetrical sphincter pressures. The sphinctometer recorded the maximum length/pressure value when its middle portion was positioning at the maximum lower oesophageal sphincter pressure. Therefore by positioning the three proximal sensors at $2.5 \mathrm{~cm}, 7.5 \mathrm{~cm}$, and $12.5 \mathrm{~cm}$ above it, the pressure points measured were actually $5 \mathrm{~cm}, 10 \mathrm{~cm}$, and $15 \mathrm{~cm}$ above the maximum lower oesophageal sphincter pressure. However, the data on the lower oesophageal sphincter generated by the sphinctometer will be the subject of another article.

\section{pH measuring assembly}

A catheter consisting of a dual channel antimony $\mathrm{pH}$ electrode (Synectics Medical, Sweden) positioned $15 \mathrm{~cm}$ apart was used to measure both intraoesophageal and intragastric $\mathrm{pH}$. This separate catheter was bonded to the pressure sensing catheter so that the proximal pH sensor was at $5 \mathrm{~cm}$ above the lower oesophageal sphincter and the distal $\mathrm{pH}$ sensor $15 \mathrm{~cm}$ below it. The distal $\mathrm{pH}$ sensor was used to investigate the relationship of gastric $\mathrm{pH}$ to gastro-oesophageal reflux, however, the gastric $\mathrm{pH}$ result is not included in this article.

\section{Pressure and $\mathrm{pH}$ recording system}

All pressure and $\mathrm{pH}$ measurements were monitored simultaneously at 8 samples/s (minimum sampling rate for oesophageal peristaltic activity was 6 samples/s) $)^{12}$ on the seven channel, 24 hour ambulatory recording device (7-MPR, Gaeltec, Isle of Skye, UK). This device used an internal computer to record the data in a compression form. All pressure changes above a preset level, in this case $6 \mathrm{~mm}$ $\mathrm{Hg}$, were recorded. Baseline data points were only stored at four second intervals when pressure changes were less than $6 \mathrm{~mm} \mathrm{Hg}$. 
This allowed the data to be reduced by a factor of between four and 20. The resulting 24 hour recording used up to a maximum of 515 kbyte of disk space. Data were downloaded onto a 410/1 Acorn Archimedes computer (32 bit, four megabyte RAM; Acorn Computers, Cambridge).

\section{STUDY PROTOCOL}

The pressure and $\mathrm{pH}$ catheters were introduced transnasally under local anaesthesia. The recorder unit functions as a computer and the recorded tracing can be viewed on the host computer's terminal allowing all pressure and $\mathrm{pH}$ channels to be checked. After correct positioning of the sphinctometer in the lower oesophageal sphincter, five dry and five wet swallows ( $5 \mathrm{ml}$ boluses) were given and responses were observed to ensure the recorder was in working order. Patients were instructed to avoid taking food or drink with $\mathrm{pH}<4$ and to carry on their normal daily activities. The event marker on the recorder was used by patients to mark supine (lying down) and upright (eating, drinking, coughing, belching) periods as well as symptomatic episodes. The patient was asked to keep a detailed record so that event marking on the recording could be correlated for later data analysis. At the completion of the recording, the data were downloaded onto the host computer for a semiautomated analysis.

\section{AMBULATORY PH AND PRESSURE DATA ANALYSIS}

Oesophageal pH data

The $\mathrm{pH}$ data were analysed in the same way as the ambulatory 24 hour $\mathrm{pH}$ monitoring data previously described.

\section{Oesophageal pressure data}

Automated analysis is partly available to analyse the oesophageal body motility data (the pressure monitored by the three pressure sensors above the sphinctometer). Since the oesophageal length varies from subject to subject; in some patients the proximal sensor was inevitably situated at the cricopharyngeus instead of pharynx when the sphinctometer was positioned in the lower oesophageal sphincter. The automated analysis only detects the pattern of pharyngeal pressure rise and not the complicated pressure wave generated by the cricopharyngeus. Therefore, the automated analysis was not used in this study to analyse the oesophageal motor response to acid reflux, instead it was analysed manually from the computer screen.

The swallow waves in the body of the oesophagus, recorded by the three sensors above the sphinctometer, were classified as 'primary activity' when related to a pharyngeal pressure rise of greater than $20 \mathrm{~mm} \mathrm{Hg}$ or to cricopharyngeal swallowing activity. If the waves were not related to such swallowing activity they were classed as 'secondary activity'.
Swallow waves were further classified and calculated manually from the computer screen as: 'peristaltic' when there was a continuous progression of contractions down the oesophagus, detected by the three sensors above the sphinctometer; 'simultaneous' when contractions occurred at the same time, in other words the velocity of the swallow wave was greater than $10 \mathrm{~cm} / \mathrm{s}$; 'non-transmitted' when the amplitude of contractions of the three pressure sensors in the oesophageal body were below $10 \mathrm{~mm} \mathrm{Hg}$ and 'low amplitude peristalsis' when the distal peristaltic amplitude was lower than $30 \mathrm{~mm} \mathrm{Hg}$. Of these, the last three types were collectively termed as ineffective activity. This meant that four types of oesophageal activity were recognised primary peristaltic activity, secondary peristaltic activity, primary ineffective activity, and secondary ineffective activity.

\section{OESOPHAGEAL ACID CLEARANCE}

In this study, an episode of gastro-oesophageal reflux was defined as beginning when the oesophageal $\mathrm{pH}$ fell below 4 , ending when the pH rose to 5, and with a minimal reflux duration of 10 seconds. The different types of oesophageal motor response during reflux episodes were studied. After acid reflux four types of acid clearance were found: when the return to $\mathrm{pH} 5$ occurred without any motor response (type $\mathrm{A}$ ); when the return to $\mathrm{pH} 5$ took place in one discrete step after a motor response (type $\mathrm{B}$ ); and when the return to $\mathrm{pH} 5$ took place in two discrete steps (type C), or in three or more discrete steps (type D). When a type $\mathrm{D}$ response occurred, the $\mathrm{pH}$ steps were labelled as initial change (I), middle changes $(M)$, and the last change $(\mathrm{L})$ when $\mathrm{pH}$ returned to 5 . If there was more than one middle change, the middle values were averaged. The mean values of initial, middle, and last changes were calculated for each patient and were compared between the two groups of patients. A comparison was made between the successive changes of $\mathrm{pH}$ in response to motor activity during initial, middle, and last changes in all patients. In addition, an attempt was made to classify the first motor response to an episode of gastrooesophageal reflux into primary or secondary activity, and further to determine whether the activity was peristaltic, simultaneous, nontransmitted, or low amplitude contractions.

\section{STATISTICAL ANALYSIS}

The Mann-Whitney U test and the Wilcoxon's signed rank test for non-parametric data were used to compare the $\mathrm{pH}$ data as appropriate. The Friedman two ways analysis of variance for non-parametric data was used to compare the successive changes of $\mathrm{pH}$ in response to motor activity in all patients. The proportion of patients with non-transmitted activity was compared between group 1 and group 2 using the Fisher exact test because of the small number of patients involved. Any $p$ value $<0.05$ was considered statistically significant. 
TABLE I Results of static manometry in 18 patients with proved gastro-oesophageal reflux. Statistical evaluation referred to comparison between two groups

\begin{tabular}{lll}
\hline & $\begin{array}{l}\text { Group 1 } \\
(n=9 \text { (oesophagitis)) }\end{array}$ & $\begin{array}{l}\text { Group 2 } \\
(n=9 \text { (normal)) }\end{array}$ \\
\hline LOS pressure (mm Hg) (mean SD)) & $8 \cdot 5(3 \cdot 1)$ & $7 \cdot 7(2 \cdot 1)$ \\
LOS length (cm) (mean (SD)) & $3 \cdot 7(1 \cdot 3)$ & $4 \cdot 3(0 \cdot 7)$ \\
ALOS (cm) (mean (SD)) & $1 \cdot 2(0 \cdot 8)$ & $1 \cdot 6(0 \cdot 7)$ \\
Simultaneous activity (5-10\%) & 0 & $2 / 9=22 \%$ \\
Non-transmitted activity (5-30\%) & $2 / 9=22 \%$ & $1 / 9=11 \%$ \\
Low-amplitude activity (5-30\%) & $3 / 9=33 \%$ & 0
\end{tabular}

LOS=lower oesophageal sphincter; ALOS=abnormal portion of LOS.

\section{Results}

The results of static manometry and ambulatory $\mathrm{pH}$ monitoring will not be discussed in detail. Briefly, the ambulatory $\mathrm{pH}$ data showed that all the patients studied had pathological gastro-oesophageal reflux and the manometry results are given in Table I. It shows no significant differences in lower oesophageal sphincter pressure, length, or the abdominal portion of lower oesophageal sphincter length between group 1 and group $2(p>0.05)$. In group 1 there was more non-transmitted and more low amplitude activity when compared with group 2; however, group 2 has more simultaneous activity. There was no significant difference in the number of patients with nontransmitted activity between the two groups $(\mathrm{p}>0 \cdot 05)$.

AMBULATORY PRESSURE AND PH MONITORING Altogether 559 episodes of gastro-oesophageal reflux in patients were analysed automatically and 1626 associated motor events were analysed manually. Of the motor events analysed, $1331(81.9 \%)$ were primary peristaltic, $174(10 \cdot 7 \%)$ primary ineffective, 46 $(2 \cdot 8 \%)$ secondary peristaltic, and $75(4 \cdot 6 \%)$ secondary ineffective activity.

The total number of reflux episodes and the reflux episodes in the upright and supine positions for group 1 and group 2 are shown in

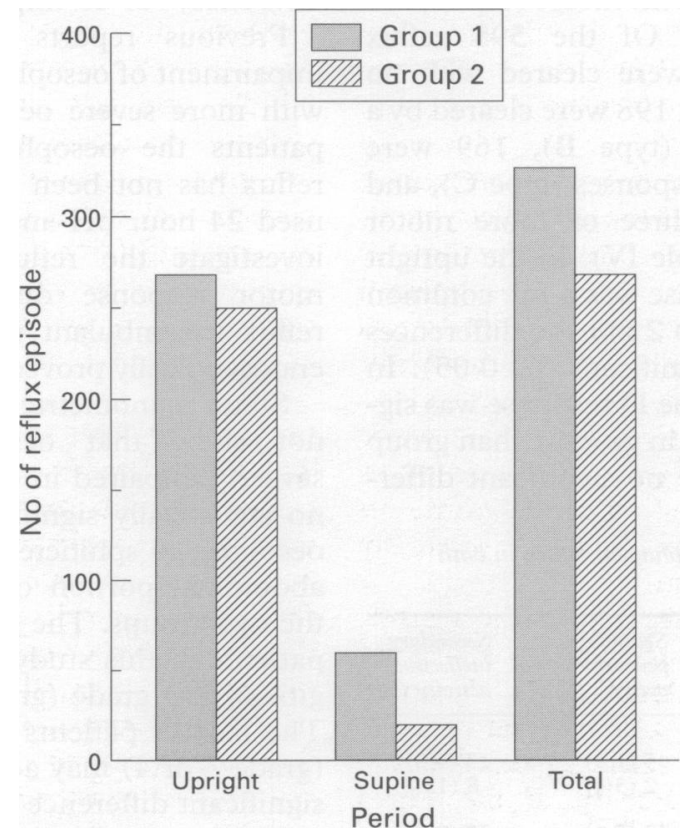

Figure 1: Reflux episodes in upright, supine, and total periods in group 1 and group 2 patients.

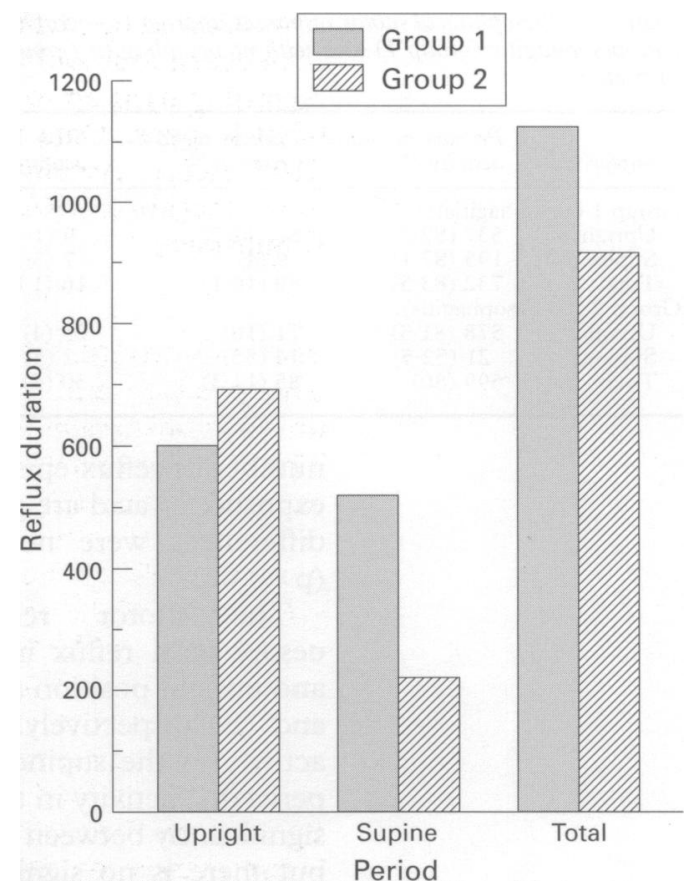

Figure 2: The duration of reflux minutes in upright, supine, and total periods in group 1 and group 2 patients.

Figure 1. Figure 2 shows the total reflux period and the duration of reflux in the upright and supine positions for both groups. Both the total
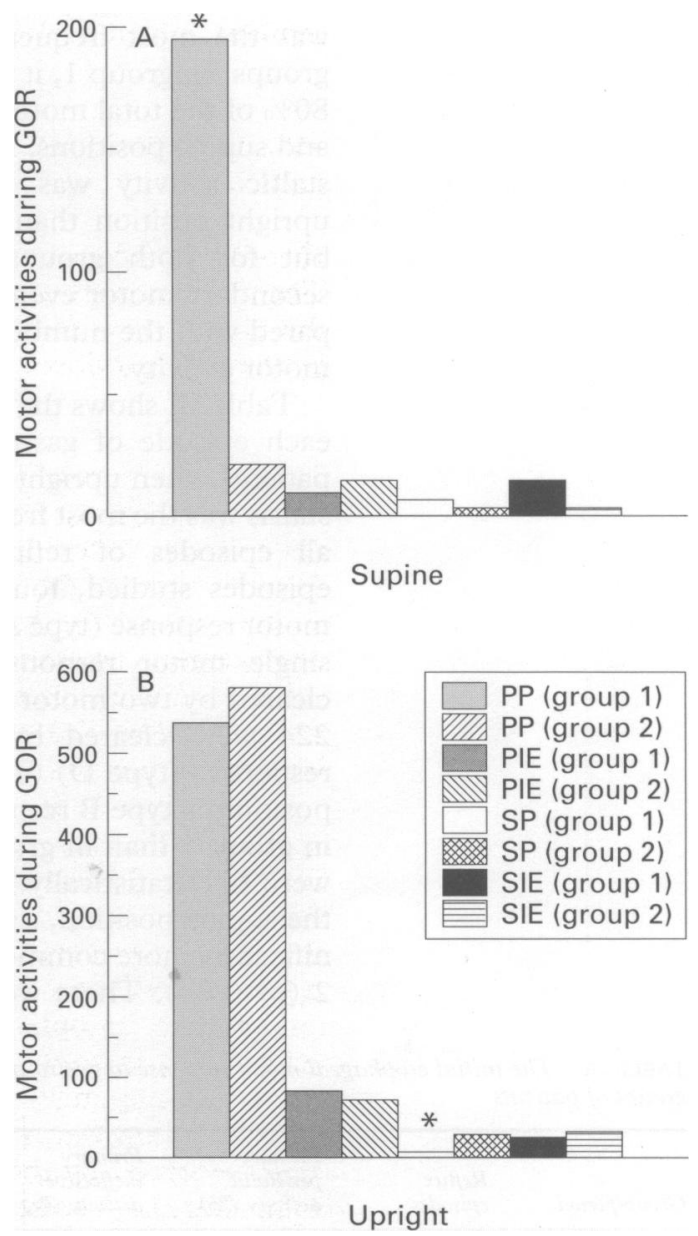

Figure 3: The motor responses after gastro-oesophageal reflux when in supine $(A)$ and upright $(B)$ positions in group 1 and group 2 patients. ${ }^{\star} p<0.05$. $P P=$ primary peristaltic activity; PIE= primary ineffective activity; $S P=$ secondary peristaltic activity; $S I E=$ secondary ineffective activity. 
TABLE II Oesophageal motor responses after gastro-oesophageal reflux in nine patients with oesophagitis (group 1) and with no oesophagitis (group 2) demonstrated by endoscopic inspection

\begin{tabular}{lllll}
\hline Group/period & $\begin{array}{l}\text { Primary peristaltic } \\
\text { activity (\%) }\end{array}$ & $\begin{array}{l}\text { Primary ineffective } \\
\text { activity (\%) }\end{array}$ & $\begin{array}{l}\text { Secondary peristaltic } \\
\text { activity (\%) }\end{array}$ & $\begin{array}{l}\text { Secondary ineffective } \\
\text { activity (\%) }\end{array}$ \\
\hline $\begin{array}{llll}\text { Group 1 (oesophagitis): } \\
\text { Upright }\end{array} \quad 537(82 \cdot 2)$ & $80(12 \cdot 3)$ & $9(1 \cdot 4)$ & $27(4 \cdot 1)$ \\
Supine & $195(87 \cdot 1)$ & $9(4)$ & $7(3 \cdot 1)$ & $13(5 \cdot 8)$ \\
Total & $732(83 \cdot 5)$ & $89(10 \cdot 1)$ & $16(1 \cdot 8)$ & $40(4 \cdot 6)$ \\
Group 2 (no oesophagitis): & $71(10)$ & $28(4)$ & $32(4 \cdot 5)$ \\
Upright & $578(81 \cdot 5)$ & $71(10)$ & $2(5)$ & $3(7 \cdot 5)$ \\
Supine & $21(52 \cdot 5)$ & $14(35)$ & $30(4)$ & $35(4 \cdot 7)$ \\
Total & $599(80)$ & $85(11 \cdot 3)$ & & \\
\hline
\end{tabular}

number of reflux episodes and the duration of exposure to acid are greater in group 1 but the differences were not statistically significant $(\mathrm{p}>0.05)$.

The motor responses after gastrooesophageal reflux in both groups in supine and upright position are shown in Figure 3 (A) and (B) respectively. The primary peristaltic activity in the supine position and secondary peristaltic activity in the upright position differ significantly between the two groups $(p<0.05)$ but there is no significant difference for any other parameter.

Table II shows the number of motor events in response to gastro-oesophageal reflux for the total reflux period and in the upright and supine positions for both groups. The values have been normalised to $100 \%$ and the motor responses are presented as percentages of the total motor activity. Primary peristaltic activity was the most frequent motor event in both groups. In group 1, it accounted for more than $80 \%$ of the total motor activity in both upright and supine positions. In group 2, primary peristaltic activity was more common in the upright position than in the supine position, but for both groups the total number of secondary motor events was small when compared with the number of episodes of primary motor activity.

Table III shows the initial motor response to each episode of gastro-oesophageal reflux in patients when upright or supine. Primary peristalsis was the most frequent motor response to all episodes of reflux. Of the 595 reflux episodes studied, four were cleared with no motor response (type A), 198 were cleared by a single motor response (type B), 169 were cleared by two motor responses (type $\mathrm{C}$ ), and 224 were cleared by three or more motor responses (type D) (Table IV). In the upright position, a type $B$ response was more common in group 1 than in group 2 but the differences were not statistically significant $(p>0 \cdot 05)$. In the supine position, a type $\mathrm{D}$ response was significantly more common in group 1 than group $2(p<0 \cdot 05)$. There were no significant differ-

TABLE III The initial esophageal motor response to gastro-oesophageal reflux in both groups of patients

\begin{tabular}{|c|c|c|c|c|c|}
\hline Group/period & $\begin{array}{l}\text { Reflux } \\
\text { episodes }\end{array}$ & $\begin{array}{l}\text { Primary } \\
\text { peristaltic } \\
\text { activity (\%) }\end{array}$ & $\begin{array}{l}\text { Primary } \\
\text { ineffective } \\
\text { activity (\%) }\end{array}$ & $\begin{array}{l}\text { Secondary } \\
\text { peristaltic } \\
\text { activity (\%) }\end{array}$ & $\begin{array}{l}\text { Secondary } \\
\text { ineffective } \\
\text { activity (\%) }\end{array}$ \\
\hline \multicolumn{6}{|c|}{ Group 1 (oesophagitis): } \\
\hline Upright & $269(100)$ & $225(83 \cdot 6)$ & $26(9 \cdot 7)$ & $5(1.9)$ & $13(4 \cdot 8)$ \\
\hline Supine & $58(100)$ & $48(82 \cdot 8)$ & $0(0)$ & $2(3 \cdot 4)$ & $8(13 \cdot 8)$ \\
\hline \multicolumn{6}{|c|}{ Group 2 (no oesophagitis): } \\
\hline Upright & $250(100)$ & $187(74 \cdot 8)$ & $22(8 \cdot 8)$ & $19(7 \cdot 6)$ & $22(8 \cdot 8)$ \\
\hline Supine & $18(100)$ & $9(50)$ & $6(33 \cdot 3)$ & $1(5 \cdot 6)$ & $2(11 \cdot 1)$ \\
\hline
\end{tabular}

ences in initial change $(p>0.05)$, middle changes $(p>0.05)$, and last change $(p>0.05)$ for the type $\mathrm{D}$ response between group 1 and group 2. For all patients, however, the successive changes in $\mathrm{pH}$ between initial, middle, and last changes were significantly different $(\mathrm{p}=0.0001)$. The changes in $\mathrm{pH}$ during last change were significantly greater than those in initial $(p=0 \cdot 001)$ and middle changes $(\mathrm{p}<0.001)$.

Figure 4 (A), (B), and (C) show examples of the ambulatory $\mathrm{pH}$ and pressure recording during periods when gastro-oesophageal reflux is absent (Fig 4 (A)) and following a reflux episode (Fig 4 (B) and (C)). Figure 4 (B) shows that primary peristalsis is generally associated with a step like increase in oesophageal $\mathrm{pH}$, whereas a minimal increase in oesophageal $\mathrm{pH}$ occurred between swallows. When low amplitude peristalsis contractions took place little change in oesophageal $\mathrm{pH}$ occurred. Figure $4(\mathrm{C})$ shows small changes of $\mathrm{pH}$ during the initial and middle changes in response to motor activities but a marked increase in $\mathrm{pH}$ takes place during the last change. The results of the lower oesophageal sphincter pressure changes during the monitoring period are not discussed in this article.

\section{Discussion}

The lower oesophageal sphincter acts as a barrier to acid gastro-oesophageal reflux. Defective basal sphincter tone or changes in sphincter pressure, due to relaxation or increased abdominal pressure, can lead to gastro-oesophageal reflux. ${ }^{13}$ There are two major mechanisms for clearing acid after reflux; oesophageal peristalsis clears the volume of the refluxate then any residual acid is neutralised by swallowed saliva. ${ }^{1}$ Delay in clearing acid may be due to ineffective motor activity, such as simultaneous, non-transmitted, or low amplitude peristaltic contractions which result in impaired volume clearance, ${ }^{2}$ or to impaired salivary function. ${ }^{7}$

Previous reports have shown increased impairment of oesophageal motility in patients with more severe oesophagitis. ${ }^{4}$ In ambulant patients the oesophageal response to acid reflux has not been fully studied. Our study used 24 hour $\mathrm{pH}$ and pressure monitoring to investigate the reflux induced oesophageal motor response during gastro-oesophageal reflux in ambulant patients with or without endoscopically proved oesophagitis.

Static manometric results in this study did not show that oesophageal motility was severely impaired in either groups. There was no statistically significant difference in lower oesophageal sphincter pressure, length, or the abdominal portion of the sphincter between the two groups. The gastro-oesophageal reflux patients in this study had either no oesophagitis or low grade (grade 1 or 2) oesophagitis. The lack of patients with severe oesophagitis (grade 3 or 4) may account for the absence of significant difference in these parameters.

This study showed that primary peristalsis was the most frequent motor response 
TABLE IV Number of $p H$ steps in response to motor activities during one reflux episode (termed as type $A$ (no pH step), type $B$ (one pH step), type $C$ (two pH steps), and type $D$ (three or more $p H$ steps)) in group 1 and group 2 patients. Statistical evaluation referred to comparison between two groups

\begin{tabular}{lclrrr}
\hline Group/period & $\begin{array}{l}\text { Reflux } \\
\text { episodes }\end{array}$ & Type A (\%) & Type B (\%) & Type C (\%) & Type D (\%) \\
\hline Group 1 (oesophagitis): & & & & \\
Upright & $269(100)$ & $2(0 \cdot 7)$ & $101(37 \cdot 6)$ & $84(31 \cdot 2)$ & $82(30 \cdot 5)$ \\
Supine & $58(100)$ & $0(0)$ & $13(22 \cdot 4)$ & $8(13 \cdot 8)$ & $37(63 \cdot 8)^{\star}$ \\
Group 2 (no oesophagitis): & & & & \\
Upright & $250(100)$ & $2(0 \cdot 8)$ & $79(31 \cdot 6)$ & $73(29 \cdot 2)$ & $96(38 \cdot 4)$ \\
Supine & $18(100)$ & $0(0)$ & $5(27 \cdot 8)$ & $4(22 \cdot 2)$ & $9(50)$ \\
\hline
\end{tabular}

${ }^{\star} \mathrm{p}=005$.

following gastro-oesophageal reflux in both groups of patients and in both the upright and supine positions. Our finding agrees with Dodds et al $^{14}$ in that primary oesophageal peristalsis is the dominant type of motor activity that occurs while oesophageal $\mathrm{pH}$ is below $\mathrm{pH} 4$, although their report was based on a 12 hour overnight study. In a more recent study in a group of healthy volunteers, using similar equipment to monitor the oesophageal body and lower oesophageal sphincter pressure, peristaltic waves were reported to be the predominant contraction leading to oesophageal acid clearance and were the commonest contraction type during reflux episodes. ${ }^{15}$ In group 1 , the total number of reflux episodes was greater and the acid exposure time was longer than in group 2, especially in the supine position, although the difference was not statistically significant.

A

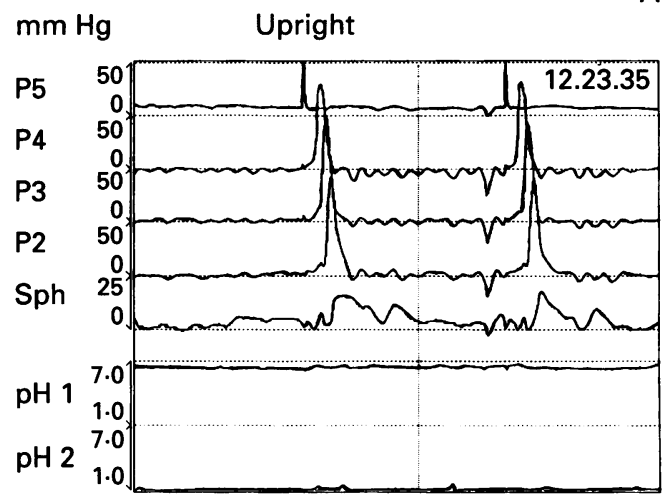

$\begin{array}{ll}\text { Time } & 12.22 .30 \\ \text { Mins/page } & 2.0\end{array}$

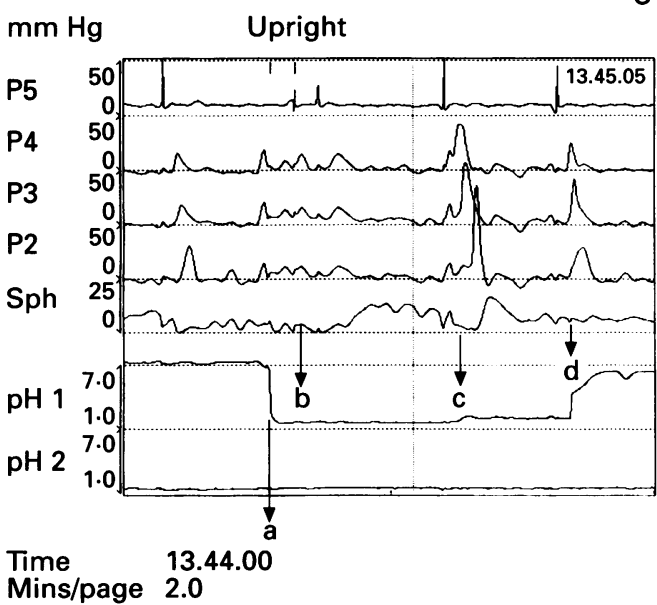

During the supine period, the primary peristaltic activity after an episode of reflux was greater in patients with oesophagitis $(p<0.05)$ than in patients without oesophagitis. The apparent anomaly of increased primary peristaltic activity in patients with oesophagitis combined with a longer duration of reflux in these patients, when they were in the supine position, may be due to two factors. Firstly, although the patients with oesophagitis demonstrated more primary peristalsis in response to reflux, they required three or more swallows to return the $\mathrm{pH}$ to normal on $63 \%$ of occasions compared with only $50 \%$ for the patients without oesophagitis $(\mathrm{p}<0.05)$. However, our finding is in agreement with those of Timmer et al ${ }^{16}$ that in patients with oesophagitis the oesophageal motor response to reflux is not impaired. A larger reflux volume could also account for the more frequent primary peristalsis and the slower return to normal $\mathrm{pH}$, as demonstrated by the higher percentage of type $\mathrm{D}$ responses and the more severe mucosal changes seen in this group. The longer supine reflux period in the group 1 patients may be an important component of the pathophysiological processes associated with the development of oesophagitis. ${ }^{17}$ Nevertheless, the development of oesophagitis is a multifactorial process, depending on components such as: frequency and duration of gastro-oesophageal reflux, contents of the refluxate, efficacy of oesophageal clearance,

$\mathrm{mm} \mathrm{Hg}$

B

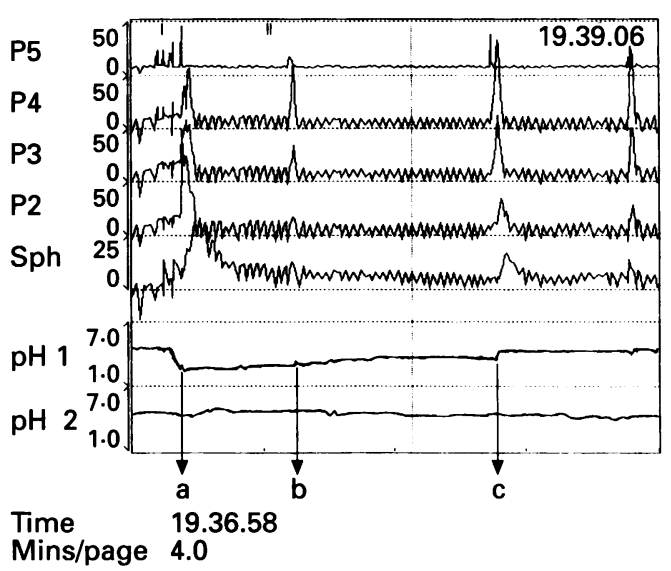

Figure 4: (A) $A$ two minute sample when no gastro-oesophageal reflux is present during the 24 hour $\mathrm{pH}$ and pressure recording. Transducer no 5 is in the pharynx, transducers 4, 3, and 2 are in the lower body of oesophagus, and transducer Sph is at the lower

oesophageal sphincter. The pH sensor 1 is situated at $5 \mathrm{~cm}$ above the lower oesophageal sphincter and pH sensor 2 at $15 \mathrm{~cm}$ below it. (B) $A$ four minute sample during gastro-oesophageal reflux. $A$ fall in $p H$ is seen in the first minute at $p H$ sensor 1 (a). Little change in $p H$ occurs when low amplitude distal oesophageal contraction takes place (b) but a distinct increment in $\mathrm{pH}$ follows the normal amplitude peristalsis (c). (C) $A$ two minute sample during gastro-oesophageal reflux. A fall in $\mathrm{pH}$ is seen in the first minute at $p H$ sensor 1 (a). Little change in $p H$ occurs at $b$ (initial change) or at $c$ (middle change) in response to motor activities, but at $d$ (last change) a marked change in $\mathrm{pH}$ takes place. 
and resistance of the oesophageal mucosa to injury by acid. 18

Secondary peristaltic activity when upright was significantly less in group 1 than in group 2 patients $(p<0.05)$. No obvious reason can be offered for this result, however, secondary peristaltic activities when upright accounted for less than $5 \%$ of total motor activities, in both groups, and may not be an important component in the clearance of gastro-oesophageal reflux.

The initial motor response of the oesophagus to acid reflux was predominately primary peristalsis, in both groups and in both positions. Salivation is stimulated when acid is present in the oesophagus, ${ }^{19}$ and this may, in turn, trigger swallowing activity and the primary peristalsis.

Where a type $\mathrm{D}$ response to reflux was demonstrated, there were no significant differences in $\mathrm{pH}$ changes after motor activities in either group ( $p>0.05)$. However, in all patients, the successive changes of $\mathrm{pH}$ in response to motor activity were significantly different $(p=0.0001)$ between initial, middle, and last changes. Last change was significantly higher than initial $(p=0.001)$ and middle changes $(p<0.001)$. The limitation of oesophageal $\mathrm{pH}$ monitoring is that although it detects acid in the oesophagus and indicates the duration of acid exposure, it does not indicate the volume of retained acid. ${ }^{20}$ In this study, there was no information on the volume of reflux or volume changes during initial and middle changes. There was also the possibility of re-reflux. For this reason the information obtained from $\mathrm{pH}$ monitoring on oesophageal clearance was limited. During the last change, however, the possibility of a significant volume of refluxate being present in the oesophagus or of further reflux was small. This may account for the fact that the last motor response during a reflux episode demonstrated the greatest acid clearance.

This is the first time it has been shown that primary oesophageal peristalsis is the most frequent response to acid gastro-oesophageal reflux in ambulant subjects. We have shown that the primary peristalsis is the major acid clearance mechanism during gastrooesophageal reflux.
The abstract form of this work was presented at the British Society of Gastroenterology meeting 15-17 September 1993 at Warwick University.

1 Kahrilas PJ. Esophageal motor activity and acid clearance. Gastroenterology Clin North Am 1990; 19: 537-50.

2 Kahrilas PJ, Dodds WJ, Hogan WJ. Effect of peristaltic dysfunction on oesophageal volume clearance. Gastroenterology 1988; 94: 73-80.

3 Hewson EG, Ott DJ, Dalton CB, Chen YM, Wu WC Richter JE. Manometry and radiology (Complementary studies in the assessment of esophageal motility disorders) Gastroenterology 1990; 626-32

4 Kahrilas PJ, Dodds WJ, Hogan WJ, Kern M, Arndorfer RC Reece A. Esophageal peristaltic dysfunction in peptic Reece A. Esophageal peristaltic dysfunction
eosphagitis. Gastroenterology 1986; 91: 897-907.

5 Anggiansah A, Wang J, Owen WJ. Does oesophagitis alter the manometric findings in patients with extended periods of acid reflux? Gut 1992; 33: S42.

6 Helm JF, Dodds WJ, Riedel DR, Teeter BC, Hogan WJ Arndorfer RC. Determinants of esophageal acid clearance in normal subjects. Gastroenterology 1985; 85: 607-12.

7 Helm JF, Dodds WJ, Pelc LR, Palmer DW, Hogan WJ, Teeter BC. Effect of esophageal emptying and saliva on clearance of acid from the esophagus. N Engl f Med 1984; 310: 284-8.

8 Emde C, Garner A, Blum A. Technical aspects of intraluminal pH-metry in man: Current status and recommendations. Gut 1987; 23: 1177-88.

9 John JF, DeMeester TR. Twenty-four-hour pH monitoring of the distal esophagus - a quantitative measure of of the distal esophagus - a quantitative measure of gastro-oes

10 Gotley DC, Barham CP, Miller R, Arnold R, Alderson D. The sphinctometer: a new device for measurement of lower oesophageal sphincter function. Br f Surg 1991; 78: 933-5.

11 Dent J. A new technique for continuous sphincter pressure measurement. Gastroenterology 1976; 71: 263-7.

12 Castell JA, Richter JE, Castell DO. Comparison of effect of decreasing sampling rates on measurement of esophagea peristaltic amplitude and durations. Gastroenterology 1988 95: 859 .

13 Dent J, Holloway RH, Toouli J, Dodds WJ. Mechanisms of lower oesophageal sphincter incompetence in patients with symptomatic gastrooesophageal reflux. Gut 1988; 29: with symp-8.

14 Dodds WJ, Kahrilas PJ, Dent J, Hogan WJ, Kern MK Arndorfer RC. Analysis of spontaneous gastroesophagea reflux and esophageal acid clearance in patients with reflux esophagitis. Fournal of Gastrointestinal Motility 1990 2 (2): 79-89.

15 Barham CP, Gotley DC, Miller R, Mills A, Alderson D. Pressure events surrounding oesophageal acid reflux episodes and acid clearance in ambulant healthy volunteers. Gut 1993; 34: 444-9.

16 Timmer R, Breumelhof R, Nadrop JHSM, Smout AJPM. Oesophageal motor responses to reflux is not impaired in reflux oesophagitis. Gut 1993; 34: 317-20.

17 DeMeester TR, Johnson LF, Guy JJ, Tosccano MS, Hall AW, Skinner DB. Patterns of gastroesophageal reflux in health and disease. Ann Surg 1976; 184: 459-70.

18 Dodds WJ, Hogan WJ, Helm JF, Dent J. Pathogenesis of reflux esophagitis. Gastroenterology 1981; 81: of reflux

19 Sonnenberg A, Steinkamp U, Weise A, Berges W, Weinbeck M, Rohner HG. Salivary secretion in reflux esophagitis. Gastroenterology 1982; 83: 889-95.

20 Skinner DB, Booth DJ, Major B. Assessment of the distal osophageal function in patients with hiatal hernia and or gastro-oesophageal reflux. Ann Surg 1970; 172 $627-7$ 